\title{
Composição da matriz de encapsulamento na formação e conversão de sementes sintéticas de pimenta-longa
}

\author{
Jonny ES Pereiraa ${ }^{1,5}$; Rodrigo da S Guedes ${ }^{2,5}$; Frederico Henrique da S Costa ${ }^{3,5}$; Gottfried Cristian B \\ Schmitz ${ }^{4}$ \\ ${ }^{1}$ Embrapa Recursos genéticos e Biotecnologia, C. Postal 02372, 70770-900 Brasília-DF; 2 ${ }^{2}$ FAC - Depto. Produção Vegetal, $69901-180$ Rio \\ Branco-Acre; ${ }^{3}$ UFLA - Dep ${ }^{\text {to }}$ Fitotecnia, 37200-000 Lavras-MG; ${ }^{4}$ Eng. Agrônomo, Rio Branco-Acre; ${ }^{5}$ Bolsista CNPq; jonny@cenargen.embrapa.br
}

\section{RESUMO}

A pimenta-longa (Piper hispidinervium C. DC.) é uma planta nativa caracterizada pela produção de safrol, um metabólito secundário usado na produção de perfumes, cosméticos e inseticidas. Neste trabalho avaliou-se o uso potencial da tecnologia de sementes sintéticas como alternativa à propagação in vitro de pimenta-longa. Foi estudada a influência da constituição da cápsula sobre a formação e conversão in vitro de unidades encapsuláveis. Sementes pré-germinadas de pimenta-longa com 21 dias de cultivo em meio de cultura de MS foram utilizadas como material de encapsulamento. A concentração de alginato de sódio utilizada na matriz de encapsulamento foi de $1,5 \%(\mathrm{p} / \mathrm{v})$ e a esta consistência se testou na água e o meio de MS nas concentrações plena (100\%), 3/4 (75\%) e 1/2 (50\%) dos sais e vitaminas, associado ou não a carvão ativado $\left(3 \mathrm{~g} \mathrm{~L}^{-1}\right)$ como elementos da cápsula. Após encapsulamento, os cultivos foram mantidos em sala de crescimento a $25 \pm 2^{\circ} \mathrm{C}$, fotoperíodo de 16 horas e intensidade luminosa de $30 \mathrm{mmol} \mathrm{m}^{-2} \mathrm{~s}^{-1}$, onde a taxa de conversão e a altura das plantas foram avaliadas quinzenalmente até 30 dias de cultivo. O delineamento utilizado foi inteiramente casualizado, em fatorial 2 x 4, com cinco repetições e dez unidades encapsuláveis por parcela. Verificou-se que o emprego de um endosperma sintético constituído por 3/4 dos sais e vitaminas de MS, acrescido de carvão ativado (3 $\left.\mathrm{g} \mathrm{L}^{-1}\right)$ (85,8\% de taxa de conversão) ou a utilização de MS pleno, independente do uso de carvão ativado (76,5\%) promoveram as melhores taxas de conversão de sementes sintéticas de pimenta-longa. A altura das plantas não foi afetada pelas concentrações de MS e adição de carvão ativado à cápsula.

Palavras-chave: Piper hispidinervum, micropropagação, sementes artificiais, unidades encapsuláveis, alginato de sódio, carvão ativado.

\begin{abstract}
Composition of the encapsulation matrix on the formation and conversion of synthetic seeds of long pepper

Long pepper (Piper hispidinervum C. DC.) is a native plant characterized by the production of safrol, a secondary metabolite used in the production of perfumes, cosmetics and insecticides. In the present work the potential use of synthetic seeds technology as an alternative to in vitro propagation of long pepper was evaluated. The influence of capsule constitution on formation and conversion of in vitro encapsulated units was also studied. Long pepper pregerminated 21-day old seeds were used as material for encapsulation. The concentration of sodium alginate used in the encapsulation matrix was $1,5 \%(\mathrm{p} / \mathrm{v})$ and this consistency was tested in water or MS at full (100\%), 3/4 (75\%) and $1 / 2(50 \%)$ concentration of salt and vitamins, associated or not to active charcoal $\left(3 \mathrm{~g} \mathrm{~L}^{-1}\right)$, as nutritional elements of the capsule. After encapsulation, cultures were maintained in a growth room at $25 \pm 2^{\circ} \mathrm{C}$ and a photoperiod of $16 \mathrm{~h}$ at $30 \mathrm{mmol} \mathrm{m}^{-2} \mathrm{~s}^{-1}$, where the conversion rate and height of the plants were evaluated for a month. The experimental design was of randomized blocks arranged in a 2 x 4 factorial scheme, with five replicates and ten encapsulated units for replicate. It was verified that The employment of a synthetic endosperm constituted by MS at $3 / 4$ concentration, enriched with active charcoal $\left(3 \mathrm{~g} \mathrm{~L}^{-1}\right)$ (85.8\% of conversion) or MS at full concentration, independently of active charcoal (76.5\%), promoted the best results on the conversion of synthetic seeds of long pepper. The height of the plants was not affected by the MS concentrations and addition of active charcoal to the capsule.
\end{abstract}

Keywords: Piper hispidinervum, micropropagation, artificial seeds, encapsulated units, sodium alginate, active charcoal.

\section{(Recebido para publicação em 13 de março de 2007; aceito em 19 de fevereiro de 2008)}

$\mathrm{U}$ ma espécie vegetal que tem despertado o interesse de empresários do ramo de fitoquímicos utilizados nas indústrias de cosméticos e bioinseticidas é a pimenta-longa (Piper hispidinervum C. D.C.), planta pertencente à família Piperaceae, encontrada naturalmente como vegetação secundária em regiões da Amazônia. Seu grande valor comercial reside na produção de um óleo essencial com elevado teor de safrol, um importante metabólito secundário usado pela indústria química na obtenção de heliotropina, amplamente utilizada como fragrância, e butóxido de piperonila (PBO), um ingrediente essencial para inseticidas biodegradáveis à base de piretrum (Wadt, 2001).

Contudo, por ainda se tratar de uma espécie em fase de domesticação e praticamente desconhecida do ponto de vista científico, pesquisas envolvendo métodos mais eficientes de propagação e conservação e que possibilitem avanços no melhoramento vegetal desta espécie ou que favoreçam a síntese de safrol, se fazem necessários (Guedes \& Pereira, 2006). Nesse contexto, poucas são as pesquisas já realizadas com o emprego de técnicas biotecnológicas para a pimenta-longa, sendo que as existentes se restringem a poucos trabalhos sobre calogênese e cultivo de células em meio líquido (Pescador et al., 2000; Valle, 2003; Costa \& Pereira, 2005; Silva et al., 2006).

A tecnologia de produção de sementes sintéticas vem se revelando como importante ferramenta em trabalhos de micropropagação e conservação in vitro de germoplasma. Além de permitir a manutenção da identidade genética do 
material vegetal e a rápida multiplicação dos propágulos, a técnica facilita a troca de germoplasma entre instituições de pesquisa e a conservação de genótipos desejáveis a baixos custos sob condições in vitro, além de permitir o estabelecimento de propágulos diretamente no campo (Maruyama et al., 1997; Nassar, 2003; Rech Filho, 2004).

Em geral, os estudos sobre encapsulamento envolvem o emprego de embriões somáticos como fonte de explantes (Castillo et al., 1998; Ara et al., 1999), havendo poucas pesquisas utilizando outros tipos de explantes como unidades encapsuláveis (Ganapathi et al., 1992; Sandoval \& Guerra, 2002; Soneji et al., 2002; Nassar, 2003; Guedes et al., 2007). Como agente encapsulante, o alginato de sódio tem sido o mais utilizado, devido à sua solubilidade à temperatura ambiente, habilidade de gel permeável com o cloreto de cálcio, boa propriedade gelificante, baixo custo, facilidade de uso e ausência de toxicidade (Guerra et al., 1999).

Entretanto, apesar dos resultados positivos já obtidos com esta tecnologia, há ainda necessidade de inovações e, sobretudo, melhorias quanto à adequação dos tipos e concentrações dos constituintes a serem introduzidos à matriz de encapsulamento ou endosperma sintético (Guerra et al., 1999; Guedes et al., 2007). Vários são os elementos comumente utilizados durante a produção de sementes artificiais, como macro e micronutrientes, vitaminas, fungicidas e sacarose (Saiprasad, 2001; Sandoval \& Guerra, 2002; Martin, 2003). No entanto, outros compostos também têm sido introduzidos na matriz de alginato com o objetivo de melhorar a conversão das unidades encapsuladas em plantas, entre os quais, citam-se osmorreguladores como sorbitol e manitol e fitorreguladores como BAP, ABA e $\mathrm{AG}_{3}$ (Nieves et al., 1998; Ara et al., 1999; Inocente, 2002).

Este trabalho objetivou avaliar a possibilidade de uso da tecnologia de sementes sintéticas como ferramenta alternativa à produção in vitro de propágulos de pimenta-longa (Piper hispidinervum C. DC.), visando estudos futuros de conservação in vitro da espé- cie. Para tanto, a influência da composição da matriz de encapsulamento na formação e conversão de sementes sintéticas de pimenta-longa, a partir de sementes pré-germinadas, foi avaliada.

\section{MATERIAL E MÉTODOS}

O experimento foi conduzido no Laboratório de Morfogênese e Biologia Molecular da Embrapa Acre, Rio Branco. Para o encapsulamento, utilizaramse como unidades encapsuláveis sementes pré-germinadas de pimenta-longa com 21 dias de cultivo (Guedes et al., 2006). Para tanto, as sementes foram desinfestadas por imersão em álcool $70 \%$ (v/v) por 1 minuto, seguido por hipoclorito de sódio 50\% (v/v) da concentração comercial por 20 minutos e, então, lavadas por três vezes em água destilada e autoclavada. Em seguida, foram colocadas para germinar em meio constituído pelos sais e vitaminas de MS (Murashige \& Skoog, 1962), acrescido de $30 \mathrm{~g} \mathrm{~L}^{-1}$ de sacarose e solidificado com $6 \mathrm{~g} \mathrm{~L}^{-1}$ de ágar. $\mathrm{O} \mathrm{pH}$ do meio foi ajustado para 5,8 $\pm 0,1$ anteriormente à adição do agente gelificante, sendo em seguida autoclavado a $121^{\circ} \mathrm{C}$ e 1,5 atm por 15 minutos para esterilização.

Após três semanas de cultivo, as sementes pré-germinadas foram inicialmente selecionadas, e então misturadas à matriz de alginato de sódio $(1,5 \%$ p/ v). Posteriormente, com o auxílio de uma pipeta automática com ponteira autoclavada (ajustada para $350 \mu \mathrm{L}$ ), as unidades encapsuláveis foram individualmente resgatadas e gotejadas em solução de $\mathrm{CaCl}_{2} \cdot 2 \mathrm{H}_{2} \mathrm{O}(50 \mathrm{mM})$, na qual permaneceram por 20 minutos para complexação. Em seguida, as sementes sintéticas, individualmente formadas por uma semente pré-germinada envolta na matriz de encapsulamento (Figura 1), foram submetidas a três lavagens em água destilada e esterilizada para a retirada do excesso de $\mathrm{CaCl}_{2} \cdot 2 \mathrm{H}_{2} \mathrm{O}$. Sequencialmente, as sementes artificiais foram imersas em solução de $\mathrm{KNO}_{3}$ (100 mM) por 20 minutos para a descomplexação, sendo em seguida novamente lavadas em água destilada e esterilizada, e colocadas em frascos de vidro de $250 \mathrm{~mL}$ de capacidade com 40 $\mathrm{mL}$ de meio de MS para emergência e desenvolvimento. Tanto a solução de alginato de sódio (Synth ${ }^{\circledR}$ ) com os respectivos tratamentos, como as soluções de $\mathrm{CaCl}_{2} \cdot 2 \mathrm{H}_{2} \mathrm{O}$ e de $\mathrm{KNO}_{3}$ foram esterilizadas por autoclavagem a $121^{\circ} \mathrm{C}$ durante 15 minutos e 1,3 atm de pressão.

Os tratamentos consistiram da influência da constituição da cápsula (água ou sais e vitaminas de MS nas concentrações $1 / 2$, 3/4 e plena do meio de MS), associado à adição ou não de carvão ativado ( $\left.3 \mathrm{~g} \mathrm{~L}^{-1}\right)$. O delineamento experimental empregado foi inteiramente casualizado, em fatorial $2 \times 4$, sendo cada tratamento representado por cinco repetições, e dez unidades encapsuladas por parcela. Quinzenalmente foi avaliada a conversão (emergência das unidades encapsuláveis) e altura das plantas por um período de 30 dias.

Para isso, após descomplexação, o material foi mantido em sala de crescimento, à temperatura de $25 \pm 2{ }^{\circ} \mathrm{C}$, fotoperíodo de 16 horas e intensidade luminosa de $30 \mathrm{mmol} \mathrm{m}^{-2} \mathrm{~s}^{-1}$. Os dados obtidos foram analisados com o emprego do programa estatístico SANEST (Zonta \& Machado, 1984) e, as médias, comparadas pelo teste de Tukey a 5\% de probabilidade. Dados expressos em percentagem (x) foram transformados para raiz quadrada do arco seno $(\mathrm{x} / 100)^{0,5}$.

\section{RESULTADOS E DISCUSSÃO}

A adição de concentrações mais elevadas do meio MS (3/4 e pleno) na matriz de encapsulamento proporcionou percentuais de conversão das sementes pré-germinadas de pimenta-longa significativamente superiores ao tratamento onde se utilizou a água como constituinte do endosperma artificial (Tabela 1). Resultados semelhantes aos obtidos neste trabalho foram observados por Sandoval \& Guerra (2002) com microbrotos de bananeira e por Rao \& Singh (1999), trabalhando com Solanum melongena. Ao contrário, Castillo et al. (1998), estudando o encapsulamento de embriões somáticos de mamão, observaram que a freqüência de regeneração dos embriões encapsulados foi significativamente afetada pela presença de sais nutritivos na cápsula, sendo os melhores resultados obtidos em unidades 
Tabela 1. Influência da constituição da matriz de encapsulamento sobre a taxa de conversão e altura (cm) de plantas de pimenta longa (influence of the encapsulation matrix in the conversion and height (cm) of long pepper plants). Rio Branco, Embrapa Acre, 2006.

\begin{tabular}{|c|c|c|c|c|c|c|c|c|c|}
\hline \multirow{4}{*}{$\begin{array}{l}\text { Época de } \\
\text { avaliação (dias) }\end{array}$} & \multicolumn{8}{|c|}{ Taxa de conversão (\%), Constituição da cápsula* } & \multirow{4}{*}{ Média } \\
\hline & \multicolumn{2}{|c|}{ Água } & \multicolumn{2}{|c|}{ MS $1 / 2$} & \multicolumn{2}{|c|}{ MS $3 / 4$} & \multicolumn{2}{|c|}{ MS pleno } & \\
\hline & \multicolumn{8}{|c|}{ carvão ativado $\left(3 \mathrm{gL}^{-1}\right)$} & \\
\hline & com & sem & com & sem & com & sem & com & sem & \\
\hline 15 & 64,9 & 52,1 & 84,7 & 54,4 & 85,8 & 60,2 & 71,1 & 73,7 & $68,4 \mathrm{~b}$ \\
\hline 30 & 65,9 & 64,4 & 87,2 & 70,0 & 85,8 & 73,7 & 72,5 & 89,0 & $76,1 \mathrm{a}$ \\
\hline Média & $65,4 \mathrm{~A}$ & $58,2 \mathrm{~A}$ & $85,9 \mathrm{~A}$ & $62,2 \mathrm{~B}$ & $85,8 \mathrm{~A}$ & $66,9 \mathrm{~B}$ & $71,8 \mathrm{~A}$ & $81,3 \mathrm{~A}$ & \\
\hline Média & & & & & & & & & \\
\hline \multirow{4}{*}{$\begin{array}{l}\text { Época de } \\
\text { avaliação (dias) }\end{array}$} & \multicolumn{8}{|c|}{ Altura de plantas $(\mathrm{cm})$, Constituição da cápsula* } & \multirow{4}{*}{ Média } \\
\hline & & & & & & & & no & \\
\hline & \multicolumn{8}{|c|}{ carvão ativado $\left(3 \mathrm{gL}^{-1}\right)$} & \\
\hline & com & sem & com & sem & com & sem & com & sem & \\
\hline 15 & 0,4 & 0,5 & 0,5 & 0,4 & 0,5 & 0,4 & 0,5 & 0,4 & $0,4 b$ \\
\hline 30 & 0,5 & 0,6 & 0,9 & 0,7 & 0,8 & 0,8 & 0,7 & 0,8 & $0,7 a$ \\
\hline Média & $0,4 \mathrm{~A}$ & $0,5 \mathrm{~A}$ & $0,7 \mathrm{~A}$ & $0,5 \mathrm{~A}$ & $0,6 \mathrm{~A}$ & $0,6 \mathrm{~A}$ & $0,6 \mathrm{~A}$ & $0,6 \mathrm{~A}$ & \\
\hline Média & \multicolumn{2}{|c|}{$0,4 \mathrm{~A}$} & \multicolumn{2}{|c|}{$0,6 \mathrm{~A}$} & & & \multicolumn{2}{|c|}{$0,6 \mathrm{~A}$} & \\
\hline
\end{tabular}

Médias seguidas de mesma letra para cada item avaliado não diferem entre si pelo teste de Tukey, $\mathrm{P}<0,05$ (means followed by the same letter within each evaluated item did not differ from each other by the Tukey test, $\mathrm{P}<0.05$ ).

* MS 1/2, MS 3/4 e MS pleno = 50\%, 75\% e 100\% de sais e vitaminas do meio de cultura de MS (Murashige \& Skoog, 1962), respectivamente (50\%, 75\% e $100 \%$ of salts and vitamins of the MS medium (Murashige \& Skoog, 1962), respectively)

encapsuladas em matriz de alginato com MS na concentração $1 \frac{1}{2}$, com $77,5 \%$ de germinação dos embriões.

Para os tratamentos onde se utilizou os sais e vitaminas de MS nas concentrações $1 / 2$ e 3/4, o acréscimo de carvão ativado (3 $\left.\mathrm{g} \mathrm{L} \mathrm{L}^{-1}\right)$ à matriz de encapsulamento promoveu resultados significativamente superiores no percentual de conversão das plantas quando comparado aos tratamentos sem a presença de carvão ativado. Por outro lado, no tratamento que se testou a concentração plena dos sais e vitaminas de MS, não foram observadas diferenças significativas na taxa de conversão das plantas de pimenta-longa com a inclusão de carvão na matriz de alginato, sugerindo que a alta concentração de sais proporcionada pelo MS na sua concentração plena foi suficiente para garantir o desenvolvimento do material. Estudando o efeito do carvão ativado e do fungicida benlate como constituintes da matriz de encapsulamento na conversão de microbrotos de bananeira cv. Grande Naine, Sandoval \& Guerra (2002) verificaram que o carvão ativado $(1,5 \mathrm{~g}$ $\left.\mathrm{L}^{-1}\right)$, associado a $1 \mathrm{~g} \mathrm{~L}^{-1}$ de benlate, além de promover o maior percentual de conversão das unidades encapsuláveis, reduziu a oxidação dos explantes, melhorando o vigor das plantas. Segundo

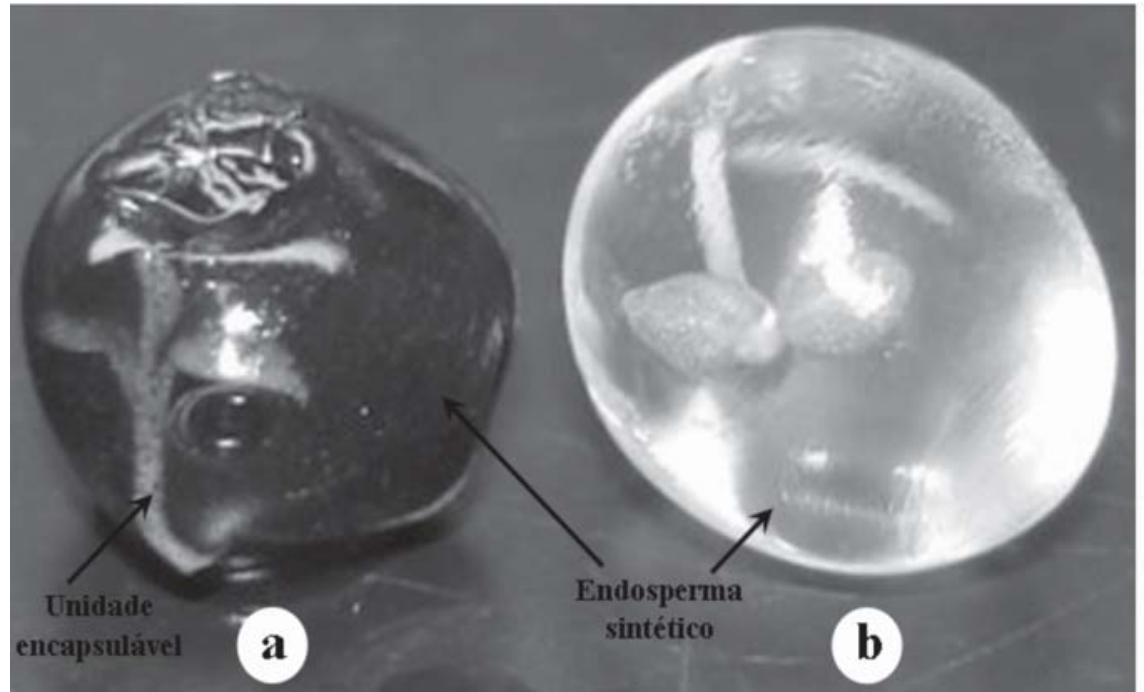

Figura 1. Aspecto da matriz de encapsulamento (endosperma sintético) com (a) e sem carvão ativado (b) na sua composição (aspect of encapsulation matrix (synthetic endosperm) with (a) and without (b) active charcoal in its composition). Rio Branco, Embrapa Acre, 2006.

Saiprasad (2001), outro efeito importante promovido pela adição de carvão ativado à matriz de alginato é o incremento na respiração dos explantes encapsulados e a adsorção de aglomerados de nutrientes que são gradativamente liberados para o explante, favorecendo assim o desenvolvimento dos cultivos. Antonietta et al. (1999) reportaram que a utilização de um endosperma sintético contendo adequada concentração de nutrientes e uma fonte de carbono promoveu ótima germinação e conversão de embriões somáticos de Citrus reticulata.

Já em relação à época de avaliação, o maior percentual médio de conversão foi obtido após 30 dias de cultivo, independente da constituição e adição de carvão ativado à matriz de alginato (Tabela 1). Quanto à altura das plântulas emergidas (convertidas), nenhuma diferença significativa foi observada para a constituição do endosperma sintético, 
diferentemente do fator época de avaliação. Desse modo, passados 30 dias da descomplexação das unidades encapsuláveis de pimenta-longa em $\mathrm{KNO}_{3}$, a altura média das plântulas alcançou $0,7 \mathrm{~cm}$, valor significativamente superior àquele observado aos 15 dias de avaliação, 0,4 cm (Tabela 1). Em relação à presença ou ausência de carvão ativado no endosperma sintético, não foram constatados efeitos significativos sobre a altura das plantas.

Conclui-se que o emprego de um endosperma sintético constituído por 75\% dos sais e vitaminas de MS, acrescido de carvão ativado ( $3 \mathrm{~g} \mathrm{~L}^{-1}$ ), ou pela concentração plena do meio MS promoveram as mais altas taxas de conversão de sementes sintéticas de pimenta-longa. A altura das plântulas não foi afetada pelas concentrações de MS e de carvão ativado na matriz de encapsulamento, após 30 dias da semeadura em meio de MS.

\section{AGRADECIMENTOS}

Ao CNPq pela concessão das bolsas de estudos.

\section{REFERÊNCIAS}

ANTONIETTA GM; EMANUELE P; ALVARO S. 1999. Effect of encapsulation on Citrus reticulata Blanco somatic embryo conversion. Plant Cell, Tissue and Organ Culture 55: 235237.

ARA A; JAISWAL U; JAISWAL VS. 1999. Germination and plantlet regeneration from encapsulated somatic embryos of mango (Mangifera indica L.). Plant Cell Reports 19: 166-170.

CASTILLO B; SMITH MAL; YADAVA UL. 1998. Plant regeneration from encapsulated somatic embryos of Carica papaya L. Plant Cell Reports 17: 172-176.

COSTA FHS; PEREIRA, JES. 2005. Seleção de auxinas para a indução de calos friáveis em Piper hispidinervum visando o estabelecimento de cultivo de células em suspensão. Horticultura Brasileira 23, suplemento. (CD ROM).
GANAPATHI TR; SUPRASANNA P; BAPAT VA; RAO PS. 1992. Propagation of banana through encapsulated shoot tips. Plant Cell Reports 11: 571-575.

GUEDES RS; COSTA FHS; PEREIRA JES. 2007. Características físicas e nutricionais da matriz de encapsulamento na produção de sementes sintéticas de pimenta-longa (Piper hispidinervum C. DC.). Revista Árvore 31: 1005-1011.

GUEDES RS; PEREIRA JES. 2006. Fitorreguladores e fonte de explantes na organogênese in vitro de pimenta longa. Horticultura Brasileira 24: 37-40, Suplemento. CD-ROM. Trabalho apresentado no $46^{\circ}$ Congresso Brasileiro de Olericultura, 2006.

GUEDES RS; SCHMITZ GCB; MACIEL SA; OLIVEIRA JP; PEREIRA JES. 2006. Avaliação da germinação de sementes e do desenvolvimento inicial de plantas de pimenta longa in vitro. Horticultura Brasileira 24: 4144. Suplemento. CD-ROM.

GUERRA MP; TORRES AC; TEIXEIRA JB. 1999. Embriogênese somática e sementes sintéticas. In: TORRES AC; CALDAS LS; BUSO JA (Ed.). Cultura de tecidos $e$ transformação genética de plantas. Brasília: Embrapa Hortaliças. p.533-568.

GUERRA MP; DAL VESCO LL; DUCROQUET JPHJ; NODARI RO; REIS MS. 2001. Somatic embryogenesis in Feijoa sellowiana: Genotype Response, Auxinic shock and Synthetic Seeds. Revista Brasileira de Fisiologia Vegetal 13: 117-128.

INOCENTE GCC. 2002. Embriogênese somática e sementes sintéticas em Feijoa sellowiana Berg.: Sistema referência e aspectos morfohistológicos e bioquímicos. 95 p. Florianópolis: Universidade Federal de Santa Catarina (Dissertação).

MARTIN KP. 2003. Clonal propagation, encapsulation and reintroduction of Ipsea malabarica (Reichb. F.) J.D. Hook., an endangered orchid. In vitro Cell and Developmental Biology-Plant 39: 322-326.

MARUYAMAE; KINOSHITA I; ISHII K; OHBA K; SAITO A. 1997. Germplasm conservation of the tropical forest trees, Cedrela odorata L., Guazuma crinita Mart., and Jacaranda mimosaefolia D. Don., by shoot tip encapsulation in calcium-alginate and storage at $12-25^{\circ} \mathrm{C}$. Plant Cell Reports 16: 393-396.

MURASHIGE T; SKOOG F. 1962. A revised medium for rapid growth and bioassays with tobacco tissue cultures. Physiologia Plantarum 15: 473-97.

NASSAR AH. 2003. Slow growth storage of encapsulated germplasm of Coffea arabica L. International Journal of Agriculture \& Biology 5: 517-520.
NIEVES N; LORENZO JC; BLANCO MA; GONZÁLEZ J; PERALTA H; HERNÁNDEZ $\mathrm{M}$; SANTOS R; CONCEPCIÓN O; BORROTO CG; BORROTO E; TAPIA R; MARTINEZ ME; FUNDORA Z; GONZÁLEZA. 1998. Artificial endosperm of Cleopatra tangerine zygotic embryos: a model for somatic embryo encapsulation. Plant Cell, Tissue and Organ Culture 54: 77-83.

PESCADOR R; ARAÚJO PS; MAAS CH; REBELO RA; GIOTTO CR; WENDHAUSEN JR R; LARGURA G; TAVARES LBB. 2000. Biotecnologia da Piper hispidinervium - Pimenta longa. Biotecnologia Ciência e Desenvolvimento 15: 18-23,

PULLMAN GS; JOHNSON S. 2002. Somatic embryogenesis in loblolly pine (Pinus taeda L.): improving culture initiation rates. Annals of Forest Science 59: 663-668.

RAO PV; SINGH B. 1999. Plant regeneration from encapsulated somatic embryos of Solanum melongena L. Plant Cell Reports 10: 7-11.

RECH FILHO A. 2004. Biorreatores de imersão temporária e unidades encapsuláveis como ferramentas na consolidação de protocolos de micropropagação de bromélias. Florianópolis: UFSC. 74 p. (Dissertação).

SAIPRASAD GVS. 2001. Artificial seeds and their application. Resonance 1: 39-47.

SANDOVAL EY; GUERRA MP. 2002. Encapsulamento de microbrotos de bananeira cv. Grand Naine. In: CONGRESSO BRASILEIRO DE FRUTICULTURA, 17. Anais..., Jaboticabal: Sociedade Brasileira de Fruticultura (CD-ROM).

SILVA TL; COSTA FHS; PEREIRA JES. 2006. Calogênese de pimenta longa é altamente dependente do tipo de explante e auxina utilizada. Horticultura Brasileira 24: 61-64, Suplemento. CD-ROM.

SONEJI JR; RAO PS; MHATRE M. 2002. Germination of synthetic seeds of pineapple (Ananas comosus L. Merr.). Plant Cell Reports 20: 891-894.

VALLE RCSC. 2003. Estratégias de cultivo de células de Pimenta longa (Piper hispidinervum) e determinação de parâmetros cinéticos. Florianópolis: UFSC. 165p. (Tese).

WADT LHO. 2001. Estrutura genética de populações naturais de pimenta longa (Piper hispidinervum C. DC.), visando seu uso e conservação. Piracicaba: USP ESALQ. 95p. (Tese).

ZONTA EP; MACHADO AA. 1984. SANEST Sistema de Análise Estatística para microcomputadores. Pelotas: UFPel, SEI. 138p. 